\title{
Plasma lipids and large bowel volatile fatty acids in pigs fed on white rice, brown rice and rice bran
}

\author{
BY YUSTINUS MARSONO*, RICHARD J. ILLMAN, JULIE M. CLARKE, \\ RODNEY P. TRIMBLE AND DAVID L. TOPPING $\dagger$ \\ CSIRO (Australia) Division of Human Nutrition, Glenthorne Laboratory, Majors Road, \\ O'Halloran Hill, SA 5158, Australia
}

(Received 10 April 1992 - Accepted 4 January 1993)

\begin{abstract}
Adult male pigs were fed on a diet containing (\% of energy) fat 25 starch 55 from white rice and providing $20 \mathrm{~g}$ fibre/pig per $\mathrm{d}$ (diet WR). In two other groups rice bran was added to the diet to provide $43 \mathrm{~g}$ fibre/d. One group received the diet unmodified (diet $\mathrm{RB}$ ), but in another (diet $\mathrm{RO}$ ) heat-stabilized unrefined rice oil replaced the palm oil. In a further group brown rice replaced white rice and provided $37 \mathrm{~g}$ fibre/pig per d (diet BR). Plasma cholesterol concentrations were similar with diets WR, RB and $B R$. With diet RO the concentration was significantly lower than with diets WR and BR but was not different from diet RB. Plasma high-density-lipoprotein-cholesterol and plasma triacylglycerols were unaffected by diet. In all groups, digesta mass rose from the caecum to the proximal colon but fell in the distal colon. Diet WR gave the lowest digesta mass while diet BR gave a significantly higher mass along the large bowel length. RB- and RO-fed pigs had equal masses of digesta which were intermediate between BR- and WR-fed pigs at all sampling sites. Pools of individual and total volatile fatty acids (VFA) in the proximal large bowel were unaffected by diet. Pools of total and individual VFA in the median and distal colon were lowest with diets WR and RB and significantly higher with diet BR. In these regions of the colon pools of acetate in RO-fed pigs did not differ from those in the BR-fed group but were higher than in other groups. However, pools of propionate and butyrate with the RO diet were significantly lower than with diet BR and the same as with diets WR and RB. Portal venous VFA concentrations were unaffected by diet. The higher large bowel digesta masses and VFA with diet BR may reflect the escape of starch from the small intestine.
\end{abstract}

Plasma cholesterol: Volatile fatty acids: Rice: Rice bran: Pig

In many developed countries coronary artery disease and other degenerative illnesses such as colo-rectal cancer are common. These disorders are believed to be due to diets high in total and saturated fat and low in complex carbohydrates (National Research Council, 1989). It is thought that to reduce the incidence of such chronic diseases fat consumption should be reduced to $<30 \%$ of energy, with saturated fat providing about $10 \%$ of energy. At the same time increased consumption of starches and fibre (non-starch polysaccharides (NSP) + lignin) is generally recommended (British Nutrition Foundation, 1990). In some countries, such as Indonesia, the national diet is presently low in fat (about $20 \%$ of energy) with most of the energy coming from starchy foods such as rice (Biro Pusat Statistik, 1988). Improved agricultural practice is leading to a better food supply in Indonesia with increases in total energy and in \% energy derived from fat. The latter increase is largely as palm and coconut oils which are believed to raise plasma cholesterol concentrations (Mattson \&

* Permanent address: Food and Nutrition Laboratory, Faculty of Agricultural Technology, Gadjah Mada University, Yogyakarta, Indonesia.

$\dagger$ For reprints. 
Grundy, 1985). Although brown rice is higher in nutrients than polished (white) rice, in Indonesia and other Asian countries the latter is the form preferred by consumers because of the stability problems due to the high oil content of the unpolished product (Coffman \& Juliano, 1987). The rice bran generated during milling is used mainly for stock-feed (Hussein \& Kratzer, 1982). Rice bran is high in NSP and in oil which is rich in monounsaturated fatty acids and low in saturated fatty acids (Babcock, 1987). This would be expected to lower plasma cholesterol (Mattson \& Grundy, 1985). Evidently rice bran has potential value as a foodstuff in such countries and the advent of stabilization means that brown rice and rice bran are now available in forms more acceptable to the consumer (Barber \& Barber, 1980; Juliano, 1985).

In the present study we fed pigs on a diet formulated from foods eaten in Indonesia based on the gross nutrient intakes of that country. This diet was low in NSP, with white rice as the major component, while palm oil was the main source of fat. In two other groups fibre was increased by feeding brown rice or rice bran in order to determine their effects on plasma lipids and on large bowel digesta mass and volatile fatty acids (VFA). The latter are formed by bacterial fermentation of NSP and may mediate some of the actions of fibre on colonic function (Fleming \& Arce, 1986). In the last group the diet included rice bran but rice oil was substituted for palm oil in order to ascertain any effects of plasma lipids.

\section{METHODS}

\section{Animals}

Twenty intact adolescent male pigs (about 5 months old) of the Large White strain were used and were obtained from a commercial pig breeder (Millwood's Piggery, Eudunda, SA 5374, Australia). The animals were housed in individual pens and fed on a standard pig production diet (Pig Grower Pellets; Milling Industries, Murray Bridge, SA 5253, Australia) as described previously (Siebert et al. 1987). All procedures described were approved formally by the Animal Care and Ethics Committees of the Division of Human Nutrition and conformed to published guidelines (National Health and Medical Research Council, CSIRO and Australian Agricultural Council, 1985).

\section{Diets}

The experimental diets were based on the gross nutrient intakes of Indonesia and the daily amounts of the uncooked rice and other ingredients fed to each animal are shown in Table 1. Apparent fat consumption in Indonesia is currently $20 \%$ of energy but is rising and is projected to reach $25 \%$ by the year 2000 so the experimental diet was formulated on the latter figure and also provided $60 \%$ of energy as carbohydrate. There were four groups of five pigs fed on diets based on white rice (WR), brown rice (BR), rice bran (RB), and rice bran + rice oil (RO). In the first three groups palm oil was the major fat source whereas in the last group heat-stabilized rice oil was substituted for the palm oil. White rice (Sunwhite), brown rice (Sunbrown), rice bran (Sunfarm) and rice oil were obtained from Rice Growers Co-operative, Leeton, NSW 2705, Australia. White rice and brown rice were cooked by boiling $25 \mathrm{~kg}$ portions for $60 \mathrm{~min}$ with just sufficient water to hydrate the rice fully. After cooking, the rice was divided into portions to provide each animal with its daily ration. The cooked rice was put in plastic bags, sealed and stored at $-20^{\circ}$ before use. Soya protein isolate (PP590) was produced by Protein Technologies International and obtained through Goodman Fielder Wattie Ltd (Regency Park, SA 5010, Australia). Palm oil was purchased from Meadow Lea Ltd (Mascot, NSW 2020, Australia). A commercial vitamin and mineral supplement (Milling Industries) was added to all diets. All the dry dietary 
Table 1. The composition of experimental diets $(\mathrm{g} / 17 \cdot 2 \mathrm{MJ}$ per $d)$

\begin{tabular}{|c|c|c|c|c|}
\hline \multirow[b]{2}{*}{ Component } & \multicolumn{4}{|c|}{ Diet } \\
\hline & WR & $\mathrm{BR}$ & RB & $\mathrm{RO}$ \\
\hline White rice & 716 & - & 664 & 664 \\
\hline Brown rice & - & 801 & - & - \\
\hline Rice bran & - & - & 163 & 163 \\
\hline Palm oil & 101 & 82 & 70 & - \\
\hline Rice bran oil & - & - & - & 70 \\
\hline Sucrose & 44 & 44 & 44 & 44 \\
\hline Lean beef & 52 & 53 & 52 & 52 \\
\hline Tuna & 103 & 103 & 103 & 103 \\
\hline Skim milk powder & 14 & 14 & 14 & 14 \\
\hline Soy protein isolate & 73 & 67 & 52 & 52 \\
\hline Calcium carbonate & 6 & 6 & 6 & 6 \\
\hline Dicalcium phosphate & 16 & 16 & 16 & 16 \\
\hline $\mathrm{NaCl}$ & 3 & 3 & 3 & 3 \\
\hline Vitamin and mineral mix* & 2 & 2 & 2 & 2 \\
\hline
\end{tabular}

* Composition: vitamin A $3 \mathrm{mg}$, vitamin D3 $45 \mu \mathrm{g}$, vitamin E $20 \mathrm{mg}$, niacin $15 \mathrm{mg}$, vitamin B-12 $12 \mu \mathrm{g}$, riboflavin $3 \mathrm{mg}$, calcium pantothenate $8 \mathrm{mg}$, biotin $50 \mu \mathrm{g}, \mathrm{Fe} 100 \mathrm{mg}, \mathrm{Cu} 10 \mathrm{mg}, \mathrm{Mn} 50 \mathrm{mg}, \mathrm{Zn} 150 \mathrm{mg}, \mathrm{I} 0.50 \mathrm{mg}$, Co $0.20 \mathrm{mg}$, Se $0.13 \mathrm{mg}$, ethoxyquin (antioxidant) $100 \mathrm{mg}$.

components were mixed thoroughly, placed in plastic freezer bags in individual plastic icecream containers, sealed and stored at $2-4^{\circ}$. One container held the daily ration for one pig. Palm oil was weighed out into individual plastic containers, sealed and stored at $2-4^{\circ}$. Rice bran was measured out on a daily basis. Both the rice and other components stored in the cold were thawed overnight, placed in individual buckets and mixed thoroughly with 21 water. The contents of the buckets were presented as a single meal at $09.30-10.30$ hours.

\section{Sampling procedures}

The sampling procedures used have been described in detail previously (Topping et al. 1993). Briefly, the animals were sedated with ketamine (Ketapex; Apex Laboratories, St Marys, NSW 2760, Australia) and then anaesthetized with halothane in $O_{2}$. The abdomen was opened and the stomach and intestines retracted to expose the hepatic portal vein from which $20 \mathrm{ml}$ blood was drawn into ice-cold tubes containing EDTA as anticoagulant. Plasma was separated by centrifugation and stored at $-20^{\circ}$ before analysis. The oesophagus and the rectum were ligated, the whole gut was excised and the caecum and colon laid out to a fixed length of $2.5 \mathrm{~m}$. The caecum was tied off from the terminal ileum and proximal colon, and the colon was subdivided into five regions (each of $500 \mathrm{~mm}$ ) which were isolated with ligatures. These sections were numbered 1-5 from the proximal colon to the rectum and their contents and that of the caecum were extruded and weighed.

\section{Analytical procedures}

The digesta contents were diluted with two volumes of ice-cold distilled water and homogenized for $20 \mathrm{~s}$ in a blender. The homogenized and diluted contents $(10 \mathrm{ml})$ were freeze-dried overnight to measure moisture content, and $50 \mathrm{ml}$ of the homogenate was frozen at $-70^{\circ}$ for the subsequent determination of VFA by gas-liquid chromatography (Topping et al. 1985). Plasma VFA, total and high-density-lipoprotein-(HDL)-cholesterol and triacylglycerols (TAG) were assayed as described previously (Topping et al. 1990). 


\section{Statistical methods}

Data are shown as means with their pooled standard errors for the number of observations indicated. Statistical evaluation was by analysis of variance incorporating a calculation of least significance difference. A value of $P<0.05$ was taken as the criterion of significance.

\section{RESULTS}

Food consumption and body weight gain

The mean body weight of the animals $(n 20)$ at the start of the experiment was 49 (SE 1$) \mathrm{kg}$. The animals found the diets palatable and all feed was consumed within 30 min of feeding which started each day at 09.30 hours. The experiment was terminated after 3 weeks and body weights were similar in all groups with means $(\mathrm{kg})$ of: WR 58; BR 57; RB 58; and RO 56 (pooled SE 2).

\section{Plasma lipids}

Plasma total cholesterol concentrations were similar in the WR-, BR-and RB-fed groups. Concentrations with diet RO were significantly lower than with diets WR and BR but not with diet RB (Table 2). The reduction was in low-density-lipoprotein (LDL) and very-lowdensity-lipoprotein (VLDL)-cholesterol (calculated by difference); HDL-cholesterol was unchanged. Total plasma TAG were also unaffected by the diet.

\section{Liver cholesterol}

Liver weights in the RO-fed group were significantly higher than with the WR- and RBfed groups. Livers of pigs fed on diet BR did not differ in weight from the other three groups. Liver cholesterol concentration and mass did not differ significantly between groups (Table 3).

\section{Caecal and colonic digesta mass and moisture content}

The masses of total digesta (i.e. caecum + sections $1-5$ of the colon) were (g): WR 433, BR 911, RB 602 and RO 712 (pooled SE 185). Diet WR gave a significantly lower mass than diet $\mathrm{BR}$ while those for diets $\mathrm{RB}$ and $\mathrm{RO}$ were similar and not significantly different from those for diets WR or BR. With all treatments digesta mass was low in the caecum, higher in section 1 of the colon and fell towards the distal colon (Fig. 1). The masses in the different regions of the colon maintained the same general relationship with the total i.e. highest with diet $\mathrm{BR}$, intermediate with diets RB and RO and lowest with diet WR.

The water content of digesta was highest in the caecum and fell along the colon (Table 4). It was the same with diets WR, RB and RO but significantly lower than with diet BR in all sections. The only exception was section 2 with diet $R B$ which did not differ from any other treatment.

\section{Large bowel VFA concentrations and pool size}

With diets WR, RB and RO the concentration of total VFA paralleled that of the digesta weight and moisture content i.e. high in the caecum and proximal colon and low in the distal colon (Fig. 2). However, with diet BR the profile was rather different with high concentrations being maintained in the distal colon. In the caecum and colonic section 1 there were no differences between any of the treatments but in all the remaining sections diet BR gave significantly higher values than diet WR. In sections 2-5 total VFA concentrations in pigs fed on diets WR and RB were the same and significantly lower than those fed on diet BR. In colonic section 2, concentrations with diet RO were the same as with diets BR and RB but significantly higher than with diet WR. In colonic sections 3 and 


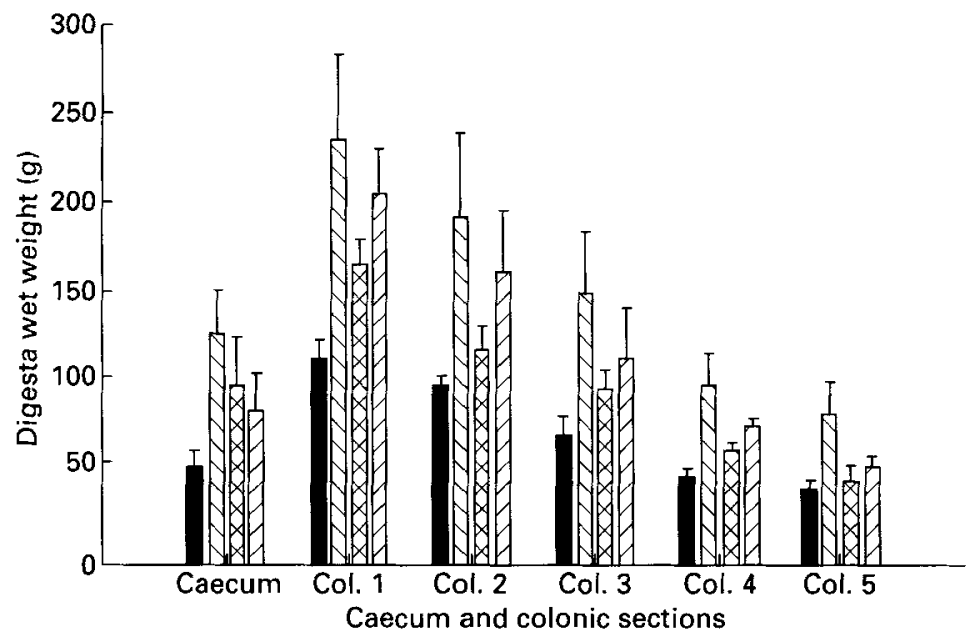

Fig. 1. Mass of digesta ( $\mathrm{g}$ wet weight) in the caecum and colonic sections (Col.) $1-5$ of pigs fed on diets based on white rice $(\square)$, brown rice $(\Theta)$, rice bran $(\otimes)$ or rice bran plus rice oil $(\varangle)$. Values are means with their pooled standard errors represented by vertical bars. For details of diets and procedures, see pp. 504-505.

Table 2. Concentration of plasma total and high-density-lipoprotein (HDL)-cholesterol and triacylglycerols $(T A G)^{*}$ in pigs fed on white rice $(W R)$, brown rice $(B R)$, rice bran $(R B)$ or rice bran plus rice bran oil $(R O) \dagger$

(Mean values for five observations per group)

\begin{tabular}{llcc}
\hline Diet & $\begin{array}{c}\text { Total cholesterol } \\
(\mathrm{mmol} / \mathrm{l})\end{array}$ & $\begin{array}{c}\text { HDL-cholesterol } \\
(\mathrm{mmol} / \mathrm{l})\end{array}$ & $\begin{array}{c}\text { TAG } \\
(\mathrm{mmol} / \mathrm{l})\end{array}$ \\
\hline WR & $2 \cdot 25^{\mathrm{a}}$ & $0 \cdot 92^{\mathrm{a}}$ & $0 \cdot 41^{\mathrm{a}}$ \\
BR & $2 \cdot 28^{\mathrm{a}}$ & $1 \cdot 00^{\mathrm{a}}$ & $0 \cdot 34^{\mathrm{a}}$ \\
RB & $2 \cdot 08^{\mathrm{ab}}$ & $0 \cdot 85^{\mathrm{a}}$ & $0 \cdot 31^{\mathrm{a}}$ \\
RO & $1 \cdot 93^{\mathrm{b}}$ & $0 \cdot 82^{\mathrm{a}}$ & $0 \cdot 37^{\mathrm{a}}$ \\
Pooled SE & $0 \cdot 14$ & 0.09 & $0 \cdot 08$ \\
\hline
\end{tabular}

${ }^{a}, b$ Values in any vertical column not sharing the same superscript letter were significantly different $(P<005)$.

* For details of procedures, see p. 505.

$\dagger$ For details of diets and their composition, see pp. 504-505 and Table 1.

Table 3. Weight of liver and concentration and mass of hepatic cholesterol in pigs* fed on white rice $(W R)$, brown rice $(B R)$, rice bran $(R B)$ or rice bran plus rice bran oil $(R O) \dagger$

(Mean values for five observations per group)

\begin{tabular}{lccc}
\hline Diet & $\begin{array}{c}\text { Liver weight } \\
(\mathrm{g})\end{array}$ & $\begin{array}{c}\text { Liver cholesterol } \\
(\mathrm{mmol} / \mathrm{kg})\end{array}$ & $\begin{array}{c}\text { Liver cholesterol } \\
\text { mass (mmol) }\end{array}$ \\
\hline WR & $752^{\mathrm{b}}$ & $8 \cdot 1^{\mathrm{a}}$ & $6 \cdot 2^{\mathrm{a}}$ \\
BR & $814^{\mathrm{ab}}$ & $7 \cdot 8^{\mathrm{a}}$ & $6 \cdot 4^{\mathrm{a}}$ \\
RB & $775^{\mathrm{b}}$ & $7 \cdot 6^{\mathrm{a}}$ & $5 \cdot 9^{\mathrm{a}}$ \\
RO & $908^{\mathrm{a}}$ & $7 \cdot 4^{\mathrm{a}}$ & $6 \cdot 7^{\mathrm{a}}$ \\
Pooled SE & 61 & $0 \cdot 5$ & $0 \cdot 5$ \\
\hline
\end{tabular}

a.b Values in any vertical column not sharing the same superscript letter were significantly different $(P<0.05)$.

* For details of procedures, see p. 505.

$\dagger$ For details of diets and their composition, see pp. 504-505 and Table 1. 
Table 4. Moisture content of caecal and colonic digesta* of pigs fed on white rice (WR), brown rice $(B R)$, rice bran $(R B)$ or rice bran plus rice oil $(R O) \dagger$

(Mean values for five observations per group)

\begin{tabular}{llccccc}
\hline & & \multicolumn{4}{c}{ Moisture content (\%) } & Pooled \\
\cline { 4 - 7 } & Region & WR & BR & RB & RO & SE \\
\hline Caecum & $82 \cdot 5^{\mathrm{b}}$ & $90 \cdot 6^{\mathrm{a}}$ & $82 \cdot 1^{\mathrm{b}}$ & $83 \cdot 5^{\mathrm{b}}$ & $3 \cdot 7$ \\
Colon: & & & & \\
section 1 & $73 \cdot 4^{\mathrm{b}}$ & $85 \cdot 1^{\mathrm{a}}$ & $77 \cdot 2^{\mathrm{b}}$ & $75 \cdot 2^{\mathrm{b}}$ & $3 \cdot 7$ \\
section 2 & $72 \cdot 0^{\mathrm{b}}$ & $81 \cdot 7^{\mathrm{a}}$ & $75 \cdot 8^{\mathrm{ab}}$ & $72 \cdot 5^{\mathrm{b}}$ & $3 \cdot 7$ \\
section 3 & $68 \cdot 8^{\mathrm{b}}$ & $79 \cdot 4^{\mathrm{a}}$ & $71 \cdot 0^{\mathrm{b}}$ & $70 \cdot 1^{\mathrm{b}}$ & $3 \cdot 0$ \\
section 4 & $66 \cdot 8^{\mathrm{b}}$ & $78 \cdot 1^{\mathrm{a}}$ & $69 \cdot 9^{\mathrm{b}}$ & $68 \cdot 7^{\mathrm{b}}$ & $3 \cdot 2$ \\
section 5 & $57 \cdot 2^{\mathrm{b}}$ & $75 \cdot 8^{\mathrm{a}}$ & $67 \cdot 3^{\mathrm{b}}$ & $65 \cdot 5^{\mathrm{b}}$ & $4 \cdot 7$ \\
\hline
\end{tabular}

a,b Values in any horizontal column not sharing the same superscript letter were significantly different $(P<0.05)$.

* For details of procedures, see p. 505.

$\dagger$ For details of diets and their composition, see pp. 504-505 and Table 1.

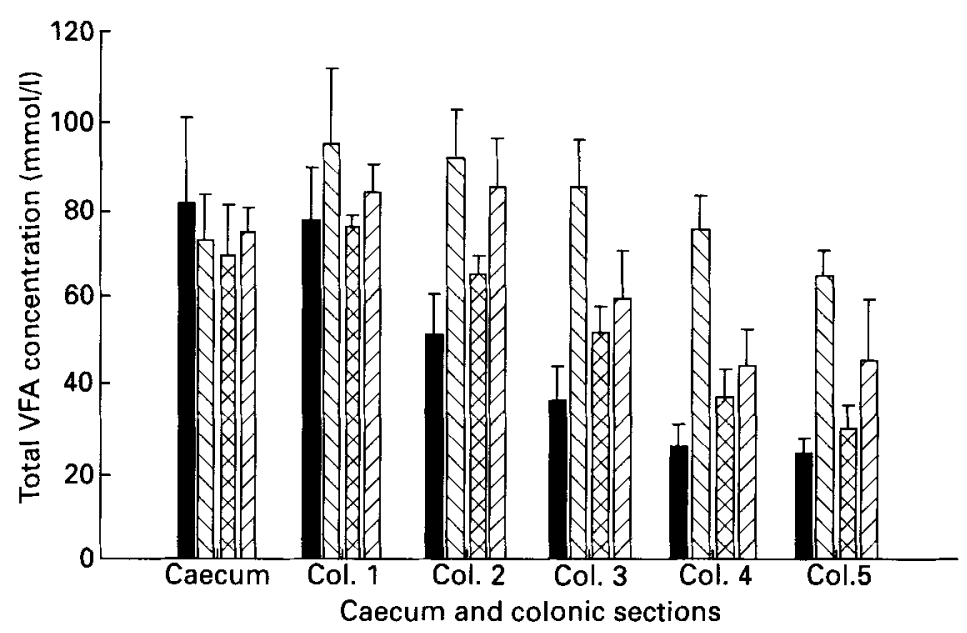

Fig. 2. Concentrations of total VFA in the caecum and colonic sections (Col.) 1-5 of pigs fed on diets based on white rice $(\square)$, brown rice $(\mathbb{Q})$, rice bran $(\mathbb{Q})$ or rice bran plus rice oil $(\square)$. Values are means with their pooled standard errors represented by vertical bars. For details of diets and procedures, see pp. 504-505.

5 diet RO did not differ from any of the other treatments but in section 4 the VFA concentrations with diet RO were lower than those with diet BR but the same as those in the WR- and RB-fed groups.

Calculation of the pools of individual VFA gave similar overall trends to those in total concentrations. In the caecum there were no effects of treatment on the pools of acetate, propionate or butyrate (Table 5). In all sections of the colon the acetate pool was significantly lower with diet WR than diet RB. In section 1 this pool with diet RB was significantly higher than that with diet WR but in all other sections there was no difference between these two treatments. In sections 1 and 2 the acetate pool for diet RO was similar to those for diets BR and RB but significantly higher than that for diet WR. In sections 3-5, acetate pools were the same as for the other three groups. The propionate pool in colonic 
Table 5. Pools of acetate, propionate and butyrate in caecal and colonic digesta* of pigs fed on white rice $(W R)$, brown rice $(B R)$, rice bran $(R B)$ or rice bran plus rice oil $(R O) \dagger$

(Mean values for five observations per group)

\begin{tabular}{|c|c|c|c|c|c|}
\hline Region & WR & BR & RB & $\mathrm{RO}$ & Pooled SE \\
\hline \multicolumn{6}{|l|}{ Acetate pool (mmol) } \\
\hline $\begin{array}{l}\text { Caecum } \\
\text { Colon: }\end{array}$ & $2 \cdot 59^{\mathrm{a}}$ & $4.55^{\mathrm{a}}$ & $3 \cdot 89^{\mathrm{a}}$ & $3 \cdot 72^{\mathrm{a}}$ & $1 \cdot 61$ \\
\hline section 1 & $3.68^{c}$ & $10 \cdot 17^{\mathrm{a}}$ & $6 \cdot 27^{b}$ & $8 \cdot 34^{\mathrm{ab}}$ & 1.92 \\
\hline section 2 & $2 \cdot 24^{c}$ & $7 \cdot 77^{\mathrm{a}}$ & $3.79^{\mathrm{bc}}$ & $6 \cdot 22^{\mathrm{ab}}$ & $1 \cdot 70$ \\
\hline section 3 & $1 \cdot 11^{\mathrm{b}}$ & $5 \cdot 78^{a}$ & $2 \cdot 12^{\mathrm{b}}$ & $3.07^{\mathrm{ab}}$ & $1 \cdot 61$ \\
\hline section 4 & $0.52^{b}$ & $3 \cdot 34^{\mathrm{a}}$ & $0.88^{b}$ & $1 \cdot 43^{\mathrm{a}}$ & 1.08 \\
\hline section 5 & $0 \cdot 34^{\mathrm{b}}$ & $2 \cdot 34^{\mathrm{a}}$ & $0 \cdot 46^{\mathrm{b}}$ & $1.09^{\mathrm{ab}}$ & 0.93 \\
\hline \multicolumn{6}{|c|}{ Propionate pool (mmol) } \\
\hline Caecum & $1 \cdot 03^{a}$ & $1 \cdot 84^{\mathrm{a}}$ & $1 \cdot 46^{\mathrm{a}}$ & $1 \cdot 23^{\mathrm{a}}$ & 0.64 \\
\hline \multicolumn{6}{|l|}{ Colon: } \\
\hline section 1 & $1 \cdot 43^{b}$ & $4 \cdot 32^{\mathrm{a}}$ & $2 \cdot 35^{\mathrm{b}}$ & $3.02^{\mathrm{ab}}$ & 0.92 \\
\hline section 2 & $0.79^{\mathrm{c}}$ & $3 \cdot 40^{\mathrm{a}}$ & $1 \cdot 33^{\mathrm{bc}}$ & $2 \cdot 00^{\mathrm{b}}$ & 0.75 \\
\hline section 3 & $0 \cdot 42^{b}$ & $2 \cdot 70^{\mathrm{a}}$ & $0.73^{\mathrm{b}}$ & $0.98^{\mathrm{b}}$ & 0.71 \\
\hline section 4 & $0 \cdot 18^{\mathrm{b}}$ & $1 \cdot 65^{\mathrm{a}}$ & $0 \cdot 32^{\mathrm{b}}$ & $0.49^{b}$ & 0.43 \\
\hline section 5 & $0 \cdot 11^{\mathrm{b}}$ & $1 \cdot 11^{\mathrm{a}}$ & $0 \cdot 18^{\mathrm{b}}$ & $1 \cdot 36^{\mathrm{b}}$ & $0 \cdot 34$ \\
\hline \multicolumn{6}{|l|}{ Butyrate pool (mmol) } \\
\hline Caecum & $0 \cdot 45^{a}$ & $0.52^{\mathrm{a}}$ & $0 \cdot 48^{\mathrm{a}}$ & $0.53^{\mathrm{a}}$ & 0.22 \\
\hline \multicolumn{6}{|l|}{ Colon: } \\
\hline section 1 & $0.69^{b}$ & $1.53^{\mathrm{a}}$ & $0.99^{\mathrm{ab}}$ & $1 \cdot 38^{\mathrm{a}}$ & $0 \cdot 32$ \\
\hline section 2 & $0.42^{\mathrm{C}}$ & $1 \cdot 47^{\mathrm{a}}$ & $0.64^{\mathrm{be}}$ & $0 \cdot 96^{\mathrm{b}}$ & $0 \cdot 34$ \\
\hline section 3 & $0 \cdot 18^{\mathrm{b}}$ & $1 \cdot 17^{\mathrm{a}}$ & $0.42^{\mathrm{b}}$ & $0.45^{\mathrm{b}}$ & $0 \cdot 32$ \\
\hline section 4 & $0-08^{\mathrm{b}}$ & $0 \cdot 65^{\mathrm{a}}$ & $0 \cdot 20^{\mathrm{b}}$ & $0 \cdot 24^{\mathrm{b}}$ & $0 \cdot 16$ \\
\hline section 5 & $0.06^{\mathrm{b}}$ & $0.47^{\mathrm{a}}$ & $0 \cdot 11^{b}$ & $0 \cdot 18^{\mathrm{b}}$ & $0 \cdot 14$ \\
\hline
\end{tabular}

\footnotetext{
a,b,c Values in any horizontal column not sharing the same superscript letter were significantly different $(P<0.05)$

* For details of procedures, see p. 505 .

$\dagger$ For details of diets and their composition, see pp. 504-505 and Table 1.
}

section 1 was highest with diet BR and lowest with diet WR. In this section diet RB was similar to diets RO and WR but significantly lower than diet BR. In sections $2-5$ diet $B R$ gave a significantly higher value than all other diets. Diets WR, RB and RO gave the same propionate pool size in sections 3-5 while in section 2 diets $W R$ and RB were similar but diet BR was significantly higher. The pool size of butyrate in section 1 with diet WR was significantly lower than with diets $B R$ and $R O$. In this region the pool size with diet RB did not differ significantly from any of the other diets.

\section{Portal venous plasma VFA}

There were no significant differences in the concentrations of total or individual VFA between the dietary treatments. The combined mean (pooled SE) values were $(\mathrm{mmol} / \mathrm{l})$ : total VFA $0.84(0.07)$, acetate $0.59(0.05)$, propionate $0.19(0.02)$ and butyrate $0.06(0.01)$.

\section{DISCUSSION}

It has been reported that brown rice and rice bran contain anti-nutritional factors such as a trypsin inhibitor (Juliano, 1985) which could reduce their food value. In the present experiments (using heat stabilized products) there were no significant differences in body weight gain suggesting that, at least in the short term, such factors did not affect feed 
conversion efficiency. Concentrations of total cholesterol were not significantly different between the animals fed on the three diets (WR, BR and RB) which contained palm oil. Rice bran has been shown to lower plasma cholesterol relative to wheat bran in rats (Topping et al. 1990) and to modify total plasma cholesterol:HDL cholesterol in man (Kestin et al. 1990); however, the present data suggest that rice bran per se did not lower cholesterol relative to the low-fibre, white rice diet. When rice oil was substituted for palm oil, plasma cholesterol was lowered by $8 \%$ relative to the corresponding rice bran diet and $18 \%$ relative to the brown rice diet. This finding is not unexpected given that palm oil is known to raise plasma cholesterol in man (Mattson \& Grundy, 1985). The effects of rice oil are explicable in terms of its content of oleate and linoleate although a specific cholesterol-lowering effect of trace components such as $\gamma$-oryzanol (Sharma \& Rukmini, 1986; Seetharamaiah \& Chandrasekhara, 1989; Nicolosi et al. 1991) cannot be excluded. None of the experimental diets significantly altered plasma HDL-cholesterol or TAG concentrations. The SE associated with plasma TAG concentrations was rather large and the cause of this variation is uncertain. Inter alia, these data suggest that the recovery of rice oil and its use in place of palm and coconut oils in the Indonesian diet might be of benefit in the future control of plasma cholesterol in that country.

Fibre raises faecal bulk through the passage of undigested fibre and increased numbers of bacteria which accumulate as a result of NSP fermentation (Schneeman, 1986). The present data obtained with white rice and rice bran are, to a fair degree, consistent with both these mechanisms. With diet WR, fibre intake was $20 \mathrm{~g} /$ pig per $\mathrm{d}$ and the total digesta mass was low. When dietary fibre was increased to $43 \mathrm{~g} /$ pig per d with rice bran, total digesta wet weight was greater by $40-50 \%$. These data accord with those of Johnson et al. (1989) who showed that in rats rice bran increased faecal bulk although the effect was slightly less than that of wheat bran at an equivalent fibre intake. Examination of the distribution of digesta along the length of the hind gut of the pigs shows that the differences by sampling site between the RB- and RO-fed groups and the other two groups were not significant in spite of increased fibre. We have noted previously with pigs fed on diets of fibre content similar to those in the present study that the wet weight of total colonic digesta was increased with the wheat bran but that site differences were not significant (Topping et al. 1993), probably due to individual variation in digesta flow along the colon.

In spite of the fact that dietary fibre as $36 \mathrm{~g} / \mathrm{pig}$ per $\mathrm{d}$ with diet $\mathrm{BR}$, the total digesta wet weight was $110 \%$ higher than with diet WR and $28-51 \%$ higher than with diet RB. These data suggest that although increased NSP intake was important it did not appear to be the sole determinant of colonic digesta mass. The most likely cause of the additional increase with diet BR was resistant starch (RS) which may arise due to the physical inaccessibility of the starch for digestion (Englyst \& Kingman, 1990) due to the presence of cell-wall material in the bran layer. It is known that in a number of foods a significant fraction of starch can escape ileal digestion and enter the large bowel (McBurney et al. 1988). This RS exists for a number of reasons including the amylose:amylopectin ratio, effects of any processing and the physical state of the food (British Nutrition Foundation, 1990). The RS content of legumes is high (Goodlad \& Mathers, 1990) and in the large bowel greater increases in digesta wet weight and water content are observed in pigs fed on navy (baked) beans than could be predicted by their NSP content (Topping et al. 1993). We have to recognize that if $\mathrm{RS}$ were contributing to the greater mass of digesta with the BR diet then the conditions of cooking and storage may be an important factor. Cooking followed by freezing increases the RS content of certain foods (British Nutrition Foundation, 1990). However, as the rice of all diets was treated in the same way in the present experiment it seems reasonable to assume that any resistance to digestion due to cooking and freezing of rice would be the same in all groups. 
Irrespective of dietary treatment, the mass of digesta and its water content were highest in the proximal colon and declined towards the distal colon. This is consistent with the predominance of bacterial NSP fermentation and the production of VFA in the proximal bowel (Argenzio \& Southworth, 1974), as reflected by high VFA concentrations in that region. A similar distribution of VFA has been noted previously in the pig (Topping et al. 1993) and in human trauma victims (Cummings et al. 1987) and stomal patients (Mitchell et al. 1985). Although all diets had the same general pattern of distribution along the hind gut, distal colonic section concentrations were significantly higher with diet BR than with diets RB and WR.

The three diets enriched in NSP raised the concentrations of VFA and, through the expansion of digesta mass and fluid volume, pool sizes were also higher. In contrast to concentration, pools are an indication of the total available for absorption and/or excretion. Inspection of the pool sizes of individual acids (Table 5) shows that the caecal pools of acetate, propionate and butyrate were the same with all diets but in the colon diet WR gave the lowest and diet BR the highest values for all acids. With diets WR, RB and RO the pools of acetate, propionate and buytrate all rose from the caecum to colonic section 1 and then declined below caecal levels in the distal colon. For example, the size of the acetate pool in colonic section 5 as a percentage of that in the caecum ranged from 12 for diet RB to 29 for diet RO. For butyrate the relative decline was greater with corresponding values of 13,23 and $34 \%$ for diets $W R, R B$ and $R O$ respectively. With diet BR the change was much less with acetate and propionate pools of 51 and $60 \%$ respectively of those in the caecum. For butyrate the fall was much less with a pool in section 5 about $90 \%$ of that in the caecum. These data are similar in many respects to recent experiments in which we have noted that large bowel digesta mass and concentrations of total VFA and propionate were raised disproportionately with navy (baked) beans (Topping et al. 1993). As mentioned previously, we believe the cause to be the same, i.e. RS which is fermented in broadly the same way as NSP. In the present study there seemed to be either preferential production of butyrate, as in man (McBurney et al. 1990), or conservation towards the distal colon. A possible reason for the RS in brown rice may be the grains themselves as rice bran has a smaller particle size than brown rice. Larger particles have a greater capacity to hold water (Kirwan et al. 1978) and their passage is more rapid than those of smaller ones (Brodribb \& Groves, 1978). Fragments of rice grains could be seen in the terminal ileum and proximal colon with diet BR and their passage along the colon might also explain the higher concentrations of VFA in the distal colon of pigs in that group.

Effects of diet on colonic butyrate area of particular interest. Butyrate is thought to be the preferred metabolic substrate for normal colonic mucosal cells (Roediger, 1982) and to inhibit the growth of transformed cells (Kruh, 1982). It may be part of the mechanism whereby fibre-rich foods could protect against colo-rectal cancer. If this is so then the general increase in the butyrate pool throughout the colon with brown rice might be useful in enhancing such protection. Although there were quite considerable differences in the distal colonic concentrations and pools of VFA and of acetate, propionate and butyrate, there were none in their portal venous plasma concentrations. This situation has been noted previously in the pig (Topping et al. 1993) where it seems that portal venous VFA are influenced only by their concentrations in the proximal colon, particularly colonic section 2. Thus, it appears that the pig differs from the rat where portal venous VFA concentrations and transport appear to be governed by caecal VFA production (Goodlad \& Mathers, 1990). This may not be surprising given that the rat is a caecal fermenter and has a specialized colonic musculature for retaining digesta in the caecum (Graham \& Aman, 1982). However, if the data from the pig are applicable to man they would suggest that faecal VFA concentrations are not indicative of those in the portal vein. This 
proposition adds a new dimension to the debate on the potential role of VFA in metabolic regulation. For example, it has been suggested that propionate formed from the hind gut NSP fermentation may play a role in the reduction of plasma cholesterol by such polysaccharides (Anderson \& Chen, 1986). However, it appears that the concentration of propionate required for the inhibition is rather higher than physiological levels (Illman et al. 1988). The present data also suggest that increased concentrations of colonic propionate were not predictive of raised portal venous levels and were unrelated to plasma total and HDL cholesterol.

We thank Mrs D. Biebrick and Mr Michael Addams for excellent assistance. Rice Growers Co-operative, H. J. Heinz Company Australia Ltd, Goodman Fielder Wattie and Bonlac Foods also gave generous material help. Y.M. was supported by the Food and Nutrition Development and Research Centre, Gadjah Mada University.

\section{REFERENCES}

Anderson, J. W. \& Chen, W. J. L. (1986). Cholesterol lowering properties of oat products. In Oats: Chemistry and Technology, pp. 309-333 [F. H. Webster, editor]. St Paul, MN: American Association of Cereal Chemists.

Argenzio, R. A. \& Southworth, M. (1974). Sites of organic acid production and absorption in gastointestinal tract of pigs. American Journal of Physiology 228, 454-460.

Babcock, D. (1987). Rice bran as a source of dietary fibre. Cereal Foods World 32, 538-539.

Barber, S. \& Barber, C. B. (1980). Rice Bran: chemistry and technology. In Rice Production and Utilisation, pp. 790-862 [B. S. Luh, editor]. Westport, CT: Avi Publishing Co. Inc.

Biro Pusat Statistik (1988). Food Balance Sheet in Indonesia, 1986. Jakarta, Indonesia: Biro Pusat Statistik.

British Nutrition Foundation (1990). Complex Carbohydrates in Foods. London: Chapman and Hall.

Brodribb, A. J. M. \& Groves, C. (1978). Effect of bran particle size on stool weight. Gut 19, 60-63.

Coffman, W. R. \& Juliano, B. O. (1987). Rice. In Nutritional Quality of Cereal Grains, pp. 101-131 [R. A. Olson and K. J. Frey, editors]. Madison, WI: American Society of Agronomy Inc.

Cummings, J. H., Pomare, E. W., Branch, W. J., Naylor, C. P. E. \& Macfarlane, G. T. (1987). Short chain fatty acids in human large intestine, portal, hepatic and venous blood. Gut 28, 1221-1227.

Englyst, H. N. \& Kingman, S. M. (1990). In Dietary Fibre, pp. 49-65 [D. Kritchevsky, C. Bonfield and J. W. Anderson, editors]. New York: Plenum.

Fleming, S. E. \& Arce, D. S. (1986). Volatile fatty acids: their production, absorption, utilization, and roles in human health. Clinics in Gastroenterology 15, 787-814.

Goodlad, J. S. \& Mathers, J. C. (1990). Large bowel fermentation in rats given diets containing raw peas (Pisum sativum). British Journal of Nutrition 64, 569-587.

Graham, H. \& Aman, P. (1982). The pig as a model in dietary fibre digestion studies. Scandinavian Journal of Gastroenterology 22 (Suppl 129), 55-61.

Hussein, A. S. \& Kratzer, F. H. (1982). Effect of rancidity on the feeding value of rice bran for chickens. Poultry Science 61, 2450-2455.

Illman, R. J., Topping, D. L., McIntosh, G. H., Trimble, R. P., Storer, G. B., Taylor, M. N. \& Cheng, B.-Q. (1988). Hypocholesterolemic effect of dietary propionate: studies in whole animals and perfused rat liver. Annals of Nutrition and Metabolism 32, 97-107.

Johnson, I. T., Gee, J. M. \& Brown, J. C. (1989). A comparison of rice bran, wheat bran and cellulose as sources of dietary fibre in the rat. Food Science and Nutrition 42F, 153-163.

Juliano, B. O. (1985). Rice bran. In Rice: Chemistry and Technology, [B. O. Juliano, editor]. St Paul, MN: The American Association of Cereal Chemists, Inc.

Kestin, M., Moss, R., Clifton, P. M. \& Nestel, P. J. (1990). Comparative effects of three cereal brans on plasma lipids, blood pressure, and glucose metabolism in mildly hypercholesterolemic men. American Journal of Clinical Nutrition 52, 661-666.

Kirwan, W. O., Smith, A. N., McConnell, A. A., Mitchell, W. D. \& Eastwood, M. A. (1974). Action of different bran preparations on colonic function. British Medical Journal 4, 187-189.

Kruh, J. (1982). Effects of sodium butyrate, a new pharmacological agent, on cells in culture. Molecular and Cellular Biochemistry 42, 62-85.

McBurney, M. I., Cuff, D. J. \& Thompson, L. U. (1990). Rates of fermentation and short chain fatty acids and gas production of six starches by human faecal microbiota. Journal of the Science of Food and Agriculture $\mathbf{5 0}$, 79-88.

McBurney, M. I., Thompson, L. U., Cuff, D. J. \& Jenkins, D. J. A. (1988). Comparison of ileal effluents, dietary fibers, and whole foods in predicting the physiologic importance of colonic fermentation. American Journal of Gastroenterology 63, 536-540. 
Mattson, F. H. \& Grundy, S. M. (1985). Comparison of effects of dietary saturated, monounsaturated, and polyunsaturated fatty acids on plasma lipids and lipoproteins in man. Journal of Lipid Research 26, $194-202$.

Mitchell, B. L., Lawson, M. J., Davies, M., Kerr-Grant, A., Roediger, W. E. W., Illman, R. J. \& Topping, D. L. (1985). Volatile fatty acids in the human intestine: studies in surgical patients. Nutrition Research 5, $1089-1092$.

National Health and Medical Research Council, CSIRO and Australian Agricultural Council (1985). Code of Practice for the Care and Use of Animals for Experimental Purposes. Canberra: Australian Government Publishing Service.

National Research Council (1989). Diet and Health: Implications for Reducing Chronic Disease Risk. Washington DC: National Academy Press.

Nicolosi, R. J., Ausman, L. M. \& Hegstead, D. M. (1991). Rice bran oil lowers serum total and low density lipoprotein cholesterol and apo B levels in nonhuman primates. Atherosclerosis 88, 133-142.

Roediger, W. E. W. (1982). The effect of bacterial metabolism on the nutrition and function of the colon mucosa: a symbiosis between man and bacteria. In Colon and Nutrition, pp. 11-26 [H. Goebel and H. Caspar, editors]. Lancaster: MTP Press.

Schneeman, B. O. (1986). Dietary fiber: physical and chemical properties, methods of analysis and physiological effects. Food Technology 40, 104-110.

Seetharamaiah, G. S. \& Chandrasekhara, N. (1989). Studies on hypocholesterolemic activity of rice bran oil. Atherosclerosis, 78, 219-223.

Siebert, B. D., Lewis, G. \& Topping, D. L. (1987). Comparative effects of diets of lean and high-fat meat on plasma lipids in the pig. Nutrition Research 7, 877-882.

Sharma, R. D. \& Rukmini, C. (1986). Rice bran oil and hypocholesterolemia in rats. Lipids 21, 715-717.

Topping, D. L., Illman, R. J., Clarke, J. M., Trimble, R. P., Jackson, K. \& Marsono, Y. (1993). Dietary fat and fiber alter large bowel and portal venous volatile fatty acids and plasma cholesterol but not biliary steroids in pigs. Journal of Nutrition (In the press).

Topping, D. L., Illman, R. J., Roach, P. D., Trimble, R. P., Kambouris, A. \& Nestel, P. J. (1990). Modulation of hypolipidemic effect of fish oils by dietary fiber in rats: studies with rice and wheat bran. Journal of Nutrition 120, 325-330.

Topping, D. L., Illman, R. J., Taylor, M. N. \& McIntosh, G. H. (1985). Effects of wheat bran porridge oats on hepatic portal venous volatile fatty acids in the pig. Annals of Nutrition and Metabolism 29, 325-331. 